\title{
Shaping and Co-Shaping Forms of Vitality in Music: Beyond Cognitivist and Emotivist Approaches to Musical Expressiveness
}

\author{
JIN HYUN KIM \\ University of Oldenburg
}

\begin{abstract}
Over the last three decades, there has been an increasing number of empirical studies on how music conveys and induces emotional expressiveness, revolving around both the longstanding discourse over compositional and performance features related to recognized or felt emotions, and more recent interest in (neuro)psychological mechanisms underlying emotions induced by music. However, the question of how expressive forms of music are shaped and co-shaped within the ongoing process of music-making and music perception has received little investigation. This paper focuses on the expressive forms of music that the developmental psychologist Daniel N. Stern refers to as 'forms of vitality', discussing how they are (co)shaped and give rise to aesthetic experience of music. The aim is the development of a theoretical framework allowing for a new research perspective on musical expressiveness - taking into account the aesthetic experience of music-in relation to the process of (co)shaping forms of vitality in music. Further, a hypothesis for and methodologies of empirical research fitting into this theoretical framework are considered, expanding the schema beyond cognitivist and emotivist approaches to musical expressiveness.
\end{abstract}

Submitted 2013 January 27; accepted June 28.

KEYWORDS: forms of vitality, musical expressiveness, aesthetic experience of music

TO develop a theoretical framework for empirical investigation of musical expressiveness moving beyond the question of how music represents or induces emotions - as characterized in cognitivist versus emotivist approaches to musical expressiveness (Scherer \& Zentner, 2001) - this paper considers expressive forms of music as "forms of vitality." The term comes from the developmental psychologist Daniel N. Stern; it is used here to characterize musical expressiveness as fundamental to the experiencing of vitality, i.e. living (Stern, 2010), rather than musical (performance) features conceived of as correlates of specific emotions perceived or felt by listeners. According to Stern, forms of vitality, shaped dynamically, allow for the coshaping of the (aesthetic) experience of others' expression - which can extend to an aesthetic object. Hence, this discussion is directed toward the question of how and to what extent aesthetic experience of musical expressiveness is related to the shaping and co-shaping of forms of vitality in music, and suggests hypothetical empirical studies with the potential to cope with this question.

\section{RESEARCH ON MUSIC AND EMOTION: SOME CRITICAL DISCUSSIONS}

Recently, empirical research on music and emotion has flourished, with much interest in the topic in both empirically and theoretically oriented scholarship. The topos of "music as a language of emotions," dating to the Romantic Era, has resurfaced in music research after the long $20^{\text {th }}$-century dominance of formalist aesthetics; this renewed interest comes in conjunction with recent scientific focus on emotion, which has long been disregarded in cognition research. In psychology-centered interdisciplinary research on emotion, [1] music increasingly is used as a stimulus for empirical-experimental studies investigating the recognition or induction of emotion. 


\section{Cognitivist v. Emotivist Approaches: Object-Subject Dichotomy}

Psychological and neuroscientific experiments on emotions related to music engage-through their hypotheses and experimental designs - the cognitivist versus emotivist philosophical theories on musical expressiveness recently debated among Anglo-American analytic philosophers (for a detailed discussion see Davies, 2003; 2010). As a result, concepts of emotions perceived and felt by listeners - emotions represented and induced through music - have become established in empirical-experimental research on music and emotion (Juslin \& Sloboda, 2001; 2010a).

Both cognitivist and emotivist philosophical theories on musical expressiveness-e.g. contour theory (Peter Kivy), resemblance theory (Stephen Davies), and persona theory (Jerrold Levinson) approach musical expressiveness in terms of perceptual qualities, rather than treating that expressiveness as the result of symbolization. The main difference between cognitivism and emotivism is their respective conception of the source of experienced musical expressiveness. In cognitivism, musical expressiveness is ascribed to musical features recognizable to listeners regardless of felt emotions that may or may not accompany recognition of musical expressiveness. Here, music itself is conceived of as the source of musical expressiveness. In contrast, emotivism emphasizes the emotions as felt by listeners and triggered by musical features; accordingly, musical expressiveness cannot be experienced without felt emotions, and therefore the subjective experience of musical expressiveness accompanied by emotions is the source of that musical expressiveness.

The differing approaches reflect the opposing positions of objectivist and subjectivist theories on aesthetic judgment and enjoyment as rooted in Western aesthetics. According to objectivist aesthetics, objects, whether works of art or not, are a source of aesthetic judgment and enjoyment. For instance, the Pythagorean theory of proportions teaches that an object composed proportionally is aesthetic due to its objective properties. Subjectivist aesthetics rather views the aesthetic subject as the source of aesthetic judgment and enjoyment, as in Shaftesbury's theory of taste claiming that aesthetic beauty is only in the mind: an object is not beautiful by virtue of its properties, but rather because the mind that forms this object is itself beautiful (Cooper, 2001, pp. 225-226).

This separation between object and subject of aesthetic perception and appreciation, fundamental to cognitivist versus emotivist theories on musical expressiveness, is reflected in the opposing concepts of perceived versus felt emotions as commonly applied in empirical research on music and emotion. According to the chosen approach, the experimental question becomes either: 1) which kind of emotion is represented through music/perceived during listening to music, or 2) which kind of emotion is induced through music/felt during listening to music. The experimental participants must consciously distinguish two kinds of emotional processing taking place in relation to musical stimuli: recognition of represented emotion, and feeling of induced emotion. In some studies, experimental participants are asked to identify one or the other; others require that they consciously attend to both.

\section{Separation Between Activity and Passivity}

In addition to the dichotomy between aesthetic object and subject, a separation between emotional expression (activity) and emotion perception or arousal (passivity) is also present both in cognitivist and emotivist aesthetic theories regarding musical expressiveness and in empirical research on music and emotion. Emotional expression is ascribed to the composer's or performer's music-making, which brings her/his emotions, or imaginings of another's emotions, into the work of music during composition or performance. Listeners are meant to react passively to this music with emotions perceived or aroused by the musical expression encoded in or performed into the corresponding score. Recognition or arousal of emotions is hence attributed to the process of music perception.

As a result, music-making as a process of expressing emotions, and music listening as a process of perceiving expressed emotions or emotion arousal, are treated as separate processes in which expressed and perceived or aroused emotions are conceived of as communicable - although the question of what mechanisms underlie this communication has not been investigated in much detail (Juslin, 2005). Moreover, most empirical research using survey methods and measurements of neural or other physiological activities has focused on the processes of music listening, as it is difficult to investigate the ongoing processes of music-making using these methods; the methods for investigation intervene in the subject of that investigation. Both the theoretical premise differentiating emotional expression on a productive side from emotion perception or arousal on a receptive side, and the methodological constraints of empirical research on music and emotion, have led to the dominance of studies on emotion perception or arousal during music listening. 


\section{Expressive Musical Features}

Early empirical studies on music and emotion have focused on musical features considered correlates of various categories of emotions, reported by and/or measured through experimental subjects as either perceived or felt. Those musical features have been analyzed in composed music (cf. Gabrielsson \& Lindström, 2001; 2010) and musical performances; the musical features of the latter comprise not only acoustic but also bodily-gestural features (Dahl \& Friberg, 2004; 2007). Some studies (Gabrielsson \& Juslin, 1996; Gabrielsson \& Lindström, 1995; Juslin, 1997) claim that music is emotionally expressive because of the correlations between musical acoustic features and perceived or felt emotions, whether basic or complex emotions:[2] for instance, in the correlations between happiness and musical features such as a fast mean tempo, high sound level, small tempo and sound level variability, bright timbre, fast tone attack, sharp contrasts in duration, and rising microintonation, among others (cf. Juslin \& Timmers, 2010, Figure 17.2).

It is, however, worth noting that several musical features identified as correlated with certain emotions are dynamic forms, encompassing temporal fluctuations (e.g. limited or broad timing variability, final ritardando) or changes of pitch and intensity (e.g. rising pitch contour, broad volume variability), rather than static forms. However, the question of how musical expressiveness emerges in the course of music-making and music perception is rarely addressed.[3] Instead, most studies have focused on the relationship between the musical features of a short excerpt from a larger piece of music and emotions induced through or perceived in that excerpt as measured or reported at a given moment.[4] To propose hypotheses for empirical studies investigating the dynamic nature of musical expressiveness, it therefore appears necessary to develop a theoretical framework providing a new research perspective on musical expressiveness.

\section{EXPRESSIVE FORMS OF MUSIC: FORMS OF VITALITY}

In its attention to dynamic expressive forms of music that can be supposed as related to musicians' or listeners' experiences,[5] the concept of "forms of vitality" recently introduced by the developmental psychologist Daniel N. Stern deserves consideration. Stern claims that the experience of vitality-in the context of psychology, as related to the experience of being alive, and applied to music, dance, theater and cinema - is grounded "in physical action and traceable mental operations" and "inherent in the act of [both physical and mental] movement" (Stern, 2010, p. 9). This grounding creates a sense of time, space, force, and directionality in the human mind (Stern, 2010, p. 4). In turn, the experience of vitality serves as a basis for experiencing others' vitality, regardless of whether others' movements are observed or not.

The experience of vitality is referred to as what Stern (1985) calls "vitality affects", such as a sense of surging, fading away, sudden explosiveness, and fleetingness. Stern $(2010$, p. 4) contends that not only sentient beings but also time-based arts allow for the experience of vitality, and therefore move us. Five dynamic events, the "fundamental dynamic pentad," give rise to the experience of vitality: movement, force, time, space, and directionality; as a whole, these result in a "Gestalt" (Stern, 2010, pp. 4-5). For Stern (2010, p. 5), vitality is a Gestalt that "emerges from the theoretically separate experiences of movement, force, time, space, and intention". Hence, it is illogical to analyze vitality in terms of each separate element. Rather, forms of vitality are conceived of as being immediately grasped from the fundamental dynamic pentad; for instance, dynamic forms of vitality such as exploding or fading can be comprehended in terms of a graph consisting of a time axis and an intensity (force) axis. Forms of vitality are concerned with the "how" rather than the "what" of felt experiences; regardless of the content - whether emotions, thoughts or actions - that felt experiences may have, specific kinds of experience are constituted through dynamic forms of vitality. According to Stern (2010), forms of vitality are "part of episodic memories" (p. 11), and serve as "the most fundamental of all felt experience" (p. 8) when dealing with one's own movements and those of others; this takes place in the experience of time-based arts.

Interestingly, some aspects of the shaping of music related to mental experience have already been discussed in detail, by the musicologist Friedrich von Hausegger at the end of the 19th century and the music pedagogue Alexander Truslit in the beginning of the 20th century. Delineating the causal relation between bodily aroused states and vocalizations, Hausegger discusses dynamic forms of sound, which are experienced as an expression of mental states, in his seminal monograph "Music as Expression (Die Musik als Ausdruck)" (1887). A shaped sound depends on retaining the body's aroused state, which, rather than allowing the affected muscle to remain in consistent contraction, makes it move toward periodic activity; 
this influences the resulting duration, intensity, height, and depth and temporal order of vocalization (Hausegger, 1887, pp. 10-11, 62). Hausegger contends that shaped vocal sounds are not only experienced as expressions of others' aroused states, but also give rise to the "co-sense (Mitempfindung)" of arousal (p. 42). He also considers this kind of phenomenon in the context of non-sentient phenomena such as music and dance.

In the monograph "Shaping and Movement in Music (Gestaltung und Bewegung in der Musik)", Truslit (1938) tackles the coupled relationship between the shaping of music and musical experience. The shaping of music is regarded as fundamental to the musical experience, which takes place during both music-making and music perception; the latter is characterized by the listeners' "co-shaping (mitgestalten)" of music (Truslit, 1938, p. 20) through their inward experience of movement (p. 27). Basing the shaping of a sound on its duration and intensity, Truslit conceives of movement as the primordial element being shaped. Movement in music is shaped by dynamics - gradations of sound intensity changing the volume of sound as perceived - in conjunction with agogics - temporal changes of sound causing its deceleration or acceleration within the given overall temporal structure - resulting together in spatio-temporal contours of music. According to Truslit, dynamics and agogics act as fundamentals of the process of musical shaping. Truslit's "dynamo-agogics" can therefore be regarded as analogous to Stern's "forms of vitality" as applied to music.

Common to Stern, Hausegger, and Truslit, whose considerations are representatively characterized by "forms of vitality," is that 1) a shape of expression has a spatio-temporal dynamic form of movement, which consists of different elements yet is irreducible; 2) this expressive shape or its shaping is not decoupled from the experience of expression, which is understood in a broader sense than emotions; 3 ) that shape/shaping gives rise to its covert co-shaping by others, which leads to a co-sense of experience among the group; and 4) points 1,2, and 3 are also valid for a non-animate phenomenon, such as music. This raises the question of to what extent the concept of "forms of vitality" can contribute to research on musical expressiveness. Crucially, this concept allows for an investigation of the way ("how") the experience of musical expressiveness is coupled with the shaping of expressive forms of music, whereas most recent studies on music and emotion have focused on the content ("what") of musical expressiveness-for instance, emotions, whether basic (Fritz et al., 2009; Juslin \& Laukka, 2004) or complex (Scherer, 2004; Zentner, Grandjean, \& Scherer, 2008) - and/or the mechanisms ("why") of emotions induced by music (Juslin \& Västfjäll, 2008; Juslin, Västfjäll, \& Lundqvist, 2010). Furthermore, expressive musical features can be considered as their holistic dynamic forms, rather than as the sum of each separable element.

Understanding "musical expressiveness" in the sense of the experience of expression-in conjunction with forms of vitality in music - shifts the focus of research on musical expressiveness to the aesthetic experience of music, a special form of musical experience not yet investigated in much detail within the scope of music and emotion research.[6] In the following section, discussion is directed toward the question of how the aesthetic experience of music can be addressed in relation to the dynamic nature of musical expressiveness being shaped and co-shaped in the course of music-making and music perception.

\section{AESTHETIC EXPERIENCE OF MUSIC}

According to John Dewey, an American philosopher and psychologist, an experience becomes an aesthetic experience when: 1) "the material experienced runs its course to fulfillment" (Dewey, 1934, p. 36), reaching "an inclusive and fulfilling close" (p. 58) "through ordered and organized movement" (p. 40) deemed "dynamic" (p. 57); and 2) such experience is rounded out into "a single coherent experience" (p. 56) with a satisfying emotional quality (cf. pp. 39-40). Dewey characterizes aesthetic experience as "emotional," yet does not consider emotions separate things labeled joy, sorrow, hope, etc. (cf. p. 43); rather, he conceives of emotions as "qualities, when they are significant, of a complex experience that moves and changes" (p. 43). In Dewey's view of aesthetic experience, the dynamic quality of emotional experience again comes into play, rather than the discrete categories of the experience's content, which can merely be recognized.

Dewey (1934, p. $48 \mathrm{ff}$.) examines the shaping of the artist's experience, which he characterizes as the interplay between doing and undergoing - a simultaneous moment of both retracing what has already been done (artistically executed) and of anticipating what to do next. Hence, artistic experience, traditionally considered an artist's executive expression, is regarded as being coupled with the aesthetic experience conventionally assigned to beholders of artworks. Based on this reciprocal and cumulative relationship between doing and undergoing, an artist shapes and reshapes their production process toward fulfillment or perfection, and in this way makes the experience provided by the work of art an aesthetic experience. Such a union of doing and undergoing also underlies the perception and appreciation of a work 
of art. According to Dewey $(1934$, p. 54), this kind of receptive act "accumulating toward objective fulfillment" goes beyond passivity; he contends that, when perceiving and appreciating an artwork, the beholder (re-)creates the artist's experience of the process of dynamic organization in the work (cf. p. 56).

Taking into account Stern's and Dewey's considerations, research on musical expressiveness which directs its focus toward aesthetic experience of music requires as a starting point an aesthetic theory doing justice to the dynamic process of shaping the experience of expression, and to the process of co-shaping that accompanies music perception and appreciation. The aesthetics of empathy ("Einfühlung"), developed in the context of psychological aesthetics at the end of the 19th century, seems appropriate to this purpose, especially in light of some recent neuroaesthetic approaches to investigating the neural mechanisms of the reciprocal relationship between doing and undergoing that are supposed to underlie the empathic aesthetic experience co-shaped while watching dance (Calvo-Merino, Glaser, Grezes, Passingham, \& Haggard, 2005; Calvo-Merino, Jola, Glaser, \& Haggard, 2008; Jola, Abedian-Amiri, Kuppuswamy, Pollick, \& Grosbas, 2012; Jola, Davis, \& Haggard, 2011) and beholding the visual arts (Di Dio \& Gallese, 2009; Freedberg \& Gallese, 2007; Gallese, 2010).

\section{Aesthetics of Empathy ('Einfühlung')}

"Einfühlung," the original German term for empathy, was first used to denote an implicit and immediate process related to an aesthetic object; later, it referred to an interpersonal process unmediated by the rational mode of thinking. This is akin to Stern's "forms of vitality", as it can be used for both a person's behavior and artistic expressive forms. Moreover, "empathy" does not only refer to (shared) emotions, but also to felt experience, either inter-subjectively shared or taking place between an aesthetic object and subject; or, more precisely, experience felt into ("ein-fühlen") others or an aesthetic object. Others' expressive behavior or expressive forms of an aesthetic object, which can be characterized in terms of Stern's "forms of vitality," are considered the source of empathy. Describing the mental process of empathy, George W. Pigman claims that "I see an expression and begin to imitate it; the expression calls forth in me the corresponding psychic experience; my psychic experience is then 'felt into' ('eingefühlt') the expression" (Pigman, 1995, p. 242).

According to the aesthetics of empathy, an aesthetic object is perceived as expressive neither due purely to its formal property - as contended in recent cognitivist theories on musical expressiveness - nor based on the imagining of a virtual subject of expression behind this object-as claimed in Jerrold Levinson's persona theory (Levinson, 2006), an emotivist take on musical expressiveness. Rather, the perception of expressiveness results from the beholders/listeners pouring themselves (including their mood) into the aesthetic object while observing/listening to that object. Following Theodor Lipps (1900, p. 416, translated by the author) "I am inwardly in or by an object, not somehow, but with my own personal quality"; the "experienced quality of myself appears as a certainty of the aesthetic object" (p. 417). The aesthetic perception and appreciation that exists within the beholder/listener is projected onto the object, which is regarded as expressive to the extent that the beholder/listener feels (cf. Lipps, 1903). The aesthetic object and one's own feelings experienced in conjunction with this object cannot be strictly separated. Moritz Geiger characterizes an (aesthetic) experience based on empathy as being unified between "the other I and my own I" (Geiger, 1911, p. 37, translated by the author). According to his interpretation of the term "Einfühlung," the "I" observing an object and the "I" felt into the object do not exist separately; my perceptions and feelings as triggered by the aesthetic object are not related to another person's expression, but rather to the objectified expression of myself, and more precisely to the correspondence between "the objectified and ongoing (actual) personality" (Lipps, 1900, p. 420). This allows for a "unity of activity and objectivity" (p. 422).

Lipps (1903) introduces, as a basic mechanism of aesthetic empathy, kinaesthetic simulation of motor action, which he calls "inner doing" (p. 186) or "inner imitation" (p. 191) - more precisely, "my experienced doing" (p. 187). This kind of action simulation is increasingly assumed to underlie the observation of action executed by others, taking up recent findings on neural mirror mechanisms matching action observation and execution (Rizzolatti \& Sinigaglia, 2007). Kinaesthetic simulation of motor action is used as a hypothesis in a considerable number of neuroscientific experiments on the understanding of action, emotion, language, among others, and recently on (tactile) sensation (Keysers \& Gazzola, 2009) and aesthetic experience (Calvo-Merino et al., 2008; Di Dio \& Gallese, 2009). The philosopher Gregory Currie has very recently pointed out that the hypothesis of the simulative processes - more precisely, the processes of motor simulation - underlying the (aesthetic) empathy which may not be accessible to consciousness, may be the most significant point to be taken from Lippsian theory on aesthetic empathy (Currie, 2011). Returning to the idea that expressive forms of music are conceived of as shaped forms of vitality giving rise 
to the (aesthetic) experience of musical expressiveness, the simulative processes underlying aesthetic empathy may also be assumed to be dynamic, i.e. changing in time, paralleling the process of co-shaping experience. Hence, the kinaesthetic image accompanying the listener's motor simulation-which underlies this co-shaping process - can be considered as unfolding in the course of aesthetic perception and appreciation of music, "tak[ing] shape in response to and in anticipation of the events" of a work of music (Currie, 2011), being shaped dynamically toward fulfillment.

\section{SUGGESTIONS FOR EMPIRICAL STUDIES ON MUSICAL EXPRESSIVENESS}

Thus far this paper has established that expressive forms of music and the aesthetic experience of musical expressiveness - including the latter's underlying processes of kinaesthetic simulation - are closely related to each other; each is dynamic, characterized as unifying shaping and co-shaping as well as action and perception. This final section offers suggestions for empirical studies appropriate to the dynamic nature of musical expressiveness, which cannot be grasped in its totality by either a cognitivist or emotivist approach. Empirical research on musical expressiveness, directed toward the relationship between the (co)shaping processes of forms of vitality in music, the aesthetic experience of musical expressiveness, and its underlying simulative processes of motor reactions, should deal not only with the process of music perception, but also with that of music-making.

Developing an empirical study able to cope with the complexity of this relationship first requires discussion of methodological considerations. The simulative processes of motor reactions, assumed as underlying the aesthetic experience of musical expressiveness, can be most thoroughly investigated using neuroimaging methods to trace the neural networks involved in the music-making experienced by musicians as aesthetically expressive; the possibility of measuring neural activation over mediofrontal regions and the motor cortex is based on the results of current research on neural networks involved in empathy (Decety, 2011). Neuroimaging techniques requiring the test participant to lie in a scanner, however, are inappropriate to investigating the process of music-making: the confines of the scanner make for unnatural bodily posture and limited movement; the noise in the scanner would prevent the participant from concentrating on musical-auditory events. Electroencephalography (EEG) does not allow the musician to move their heads freely, as it is difficult to remove motor artifacts from EEG signals. Functional nearinfrared spectroscopy (fNIRS) technology, as explored in a pilot study carried out by the author and colleagues using NIRScout, a portable NIRS system, imposes minimal physical constraints on the participant (when playing piano or a string instrument); nonetheless, current neuroimaging techniques require many more improvements to be reliable tools for investigating the process of music-making. On the whole, the question of what the dynamic processes of kinaesthetic simulation underlying the process of musical shaping towards fulfillment (and the co-shaping process taking place in music perception as well) look like can be most efficiently addressed by investigating the neurodynamic processes involved in musicmaking and music perception; such an approach does more justice to the temporal process of (co)shaping a piece of music than current structure- or function-oriented neuroscientific methods.

The issue of whether and how aesthetic experience can be made accessible by measuring the neural activity or other bodily activities leads to further methodological considerations, concerning the relationship between first-person and third-person data. As the first-person aesthetic experience is conceived of as "subjective," most experimental and empirical research at present has approached phenomenal experience from the "objective" third-person perspective. The first-person perspective has often been included into experimental design only "in a very weak sense" (Gallagher \& Sørensen, 2006, p. 120) - namely, that while the participants are asked to report their experiences during the experiment, vocally or by pushing buttons, in most cases they are also instructed to focus on experimental stimuli rather than their experiences. This leaves the relationship between such experimentally induced first-person perspectives, phenomenal experience, and third-person data an open question (Northoff \& Heinzel, 2006).

An examination of the relationship between first- and third-person perspectives is conceived of as only possible when based on first-person experiences; this requires the development of new first-person methodologies. Developed in France beginning in the mid-1990s within the scope of a neurophenomenological research program, neurophenomenology attempts to incorporate philosophicalphenomenological approaches into neuroscientific research (Petitmengin, Baulac, \& Navarro, 2006; Petitmengin, Navarro, \& Le Van Quyen, 2007; Lutz, Lachaux, Martinerie, \& Varela, 2002; Varela, 1996), exploring the possibility of mutual influence between experimental participants' neural activities and the structures of their first-person experiences. A technique of phenomenological interview (Petitmengin, 2006; 2007 ; 2011) offers access to ostensibly subjective experience correlated with neural activations, allowing for the detection of preictal symptoms preceding epileptic seizures (Petitmengin et al., 2006). The current 
research on first-person experience using the techniques of the phenomenological interview aims at producing a model for the (generic) structures of experience, especially temporal structures, from interview data (Petitmengin, 2006; 2011), which can then be incorporated into analysis of the (temporal) structures of the third-person data of neural activities. Neurophenomenological approaches are well-suited for empirical study of the relationship between the aesthetic experience of musical expressiveness emerging in the process of music-making and its underlying simulative processes of motor reactions. While in-depth interview techniques collect general descriptions of musicians' experiences, including their beliefs and opinions, the phenomenological interview techniques allow for retrospection directly related to the aesthetic experience of musical expressiveness that has just taken place during the music-making; this is recalled, for instance, in terms of specific perception modalities, bodily attention and conscious images, etc. Furthermore, the process of music-making is not disrupted by a post-performance phenomenological interview. The first-person descriptions of one subject are compared to those of other subjects, attempting to find the generic (especially temporal) structures of experience, which are then related to - rather than reduced to - the (especially temporal) structures analyzed from the third-person data of neural activities. Developing a neurophenomenological study to investigate the aesthetic experience of music, however, remains highly challenging, given that temporal structures from neuroimaging data can be analyzed most efficiently when using a neurodynamic approach, whereas at present structure- and function-oriented neuroscientific approaches are dominant. The current state of phenomenological interview techniques also requires further development to investigate effectively the (generic temporal structures of) aesthetic experience of music.

The next methodological step to be considered is whether and how the forms of vitality in music being shaped in the process of music-making can be related to the structures of experience delineated by a neurophenomenological study. Up until now, musical performance features have largely been analyzed in relation to discrete emotional categories, and the dynamic expressive forms of music have rarely been related to the (co)shaping process unifying doing and undergoing. With regard to the process of music perception, several experiments call for the participants to realize this co-shaping process in an observable or measurable way, e.g. by drawing a continuous line while listening to music (Godøy, Haga, \& Jensenius, 2006; Küssner, Prior, Gold, \& Leech-Wilkinson, 2012; Truslit, 1938). Taking into account the thesis developed in this paper that forms of vitality in music shaped by a musician lead to their co-shaping by a listener, the listeners' co-shaping processes - in conjunction with continuous response methodology (cf. Schubert, 2010) concerning musical expressiveness as experienced by listeners during the process of a musician's music-making - can be incorporated into the investigation of the process of music-making.

A hypothesis of the empirical study on musical expressiveness to be developed beyond a cognitivist and emotivist approach might be - as in the author's 2010 case study (Kim, Demey, Moelants, \& Leman, 2010) - that musical performance by professional musicians would be neither an act of mere expression of the performer's or an imagined person's emotions, nor an act of representation of emotions; rather, it would be a process of going along with music, an empathic devotion of the self to the music in shaping its production toward fulfillment or perfection, largely based on automatic processes available through embodied knowledge of the piece of music and guided by action-perception loops. To test this hypothesis, different conditions of music performance can be compared. In a case study, the author and colleagues (Kim et al., 2010) used two conditions of music performance which may have an impact on the empathic process underlying that performance: a sight-reading performance and a practised performance of a single piece not previously performed by the experimental participants. To relate the aesthetic experience of musical expressiveness to the process of shaping forms of vitality in music towards an inclusive and fulfilling close, different conditions of music performance to be compared may include a musical passage analyzed and interpreted by the musician as musically fulfilled and another, unfulfilled passage from the same piece of music.

To understand the dynamic nature of musical expressiveness, further research might be directed toward the role of episodic memories in the experience of musical expressiveness on the one hand and the time- and anticipation-based aspect of the perception and apprehension of musical expressiveness on the other. With regard to the latter, the musicologist and theorist Leonard B. Meyer's seminal work "Emotion and Meaning in Music" (1956) serves as a point of departure in terms of forms of vitality in music and emotional experience. A more psychologically-based approach to expectation in music perception has recently been discussed in the monograph "Sweet Anticipation: Music and the Psychology of Expectation" (2006) by the cognitive musicologist David Huron. In cognitive neuroscience of music, a recent experiment on intra-musical meaning has used hypotheses based on the expectation deriving from inner musical logic (Koelsch, 2011), following previous similar approaches to musical syntax (Koelsch, 2009; Koelsch, Fritz, Schulze, Alsop, \& Schlaug, 2005; Tillmann 2005; Tillmann, Janata, \& Bharucha 
2003). Empirical studies appropriate to addressing the ways in which the (aesthetic) experience of musical expressiveness emerges in the process of (co)shaping forms of vitality in music can be designed by working from these theories and the results of related empirical studies.

\section{NOTES}

[1] The disciplinary distribution of scholarship in research on music and emotion is well represented in the two major volumes on this topic (Juslin \& Sloboda, 2001; 2010a). See also several research institutes focusing on emotion, such as the Geneva Emotion Research Group, part of a multidisciplinary centre for the affective sciences at the University of Geneva/Switzerland, and the Cluster of Excellence "Languages of Emotion" at the Freie Universität Berlin/Germany.

[2] Recent debate about what kind of emotions music induces has introduced the term "musical emotions," an abbreviation for emotions induced by music (Juslin \& Laukka, 2004; Juslin \& Sloboda, 2010a; Zentner, Grandjean, \& Scherer, 2008). Zentner, Grandjean, and Scherer (2008) claim that musical emotions consist of emotional categories subtler than those of basic emotions, whereas Juslin and Laukka (2004) and Fritz et al. (2009) hold that music induces basic emotions.

[3] For a detailed discussion see Kim (2010).

[4] In most neuroscientific experiments on music perception and cognition, the excerpts from a piece of music used as stimuli are less than one minute in duration. This very limited duration is due to current neuroimaging techniques and analysing methods, which are oriented toward neurocognitive structures or functions rather than based on neurodynamic approaches. Empirical research on music and emotion has only very recently taken up methodological considerations concerning the measurement of experimental participants' continuous emotional reactions to stimuli in behavioral experimental design (cf. Schubert, 2010).

[5] In the 1950s, the philosopher Susanne K. Langer contended that an isomorphism exists between the structure of music and the structure of feeling, claiming that expressive forms of music should be conceived of as forms of 'feeling' - "in its broadest sense, meaning everything that can be felt, from physical sensation, pain and comfort, excitement and repose, to the most complex emotions, intellectual tensions, or steady feeling-tones of a conscious human life" (Langer, 1960 [1957], p. 249).

[6] Juslin and Sloboda (2010b) point out that investigating the aesthetic experience of music is a desideratum in music and emotion research.

\section{REFERENCES}

Calvo-Merino, B., Glaser, D.E., Grezes, J., Passingham, R.E., \& Haggard, P. (2005). Action observation and acquired motor skills: An fMRI study with expert dancers. Cerebral Cortex, Vol. 15, No. 8, pp. 1243-1249.

Calvo-Merino, B., Jola, C., Glaser, D.E., \& Haggard, P. (2008). Towards a sensorimotor aesthetics of performing art. Consciousness and Cognition, Vol. 17, No. 3, pp. 911-922.

Cooper, A. (Third Earl of Shaftesbury) (2001). Characteristics of Men, Manners, Opinions, Times. Indianapolis: Liberty Fund.

Currie, G. (2011). Empathy for objects. In: A. Coplan \& P. Goldie (Eds.), Empathy: Philosophical and Psychological Perspectives. Oxford: Oxford University Press, pp. 82-97.

Dahl, S., \& Friberg, A. (2004). Expressiveness of musician's body movements in performances on marimba. In: A. Camurri \& G. Volpe (Eds.), Gesture-Based Communication in Human-Computer Interaction: 5th International Gesture Workshop, GW 2003, Genova, Italy, April 15-17, 2003, Selected Revised Papers. LNAI 2915 Berlin/Heidelberg: Springer, pp. 479-486. 
Dahl, S., \& Friberg, A. (2007). Visual perception of expressiveness in musicians' body movements. Music Perception, Vol. 24, No. 5, pp. 433-454.

Davies, S. (2003). Themes in the Philosophy of Music. Oxford: Oxford University Press.

Davies, S. (2010). Emotions expressed and aroused by music: Philosophical perspectives. In: P.N. Juslin \& J. Sloboda (Eds.), Handbook of Music and Emotion: Theory, Research, and Applications. Oxford: Oxford University Press, pp. 15-43.

Decety, J. (2011). Dissecting the neural mechanisms mediating empathy. Emotion Review, Vol. 3, No. 1, pp. 92-108.

Dewey, J. (1934). Art as Experience. New York: Penguin.

Di Dio, C., \& Gallese, V. (2009). Neuroaesthetics: A review. Current Opinion in Neurobiology, Vol. 19, No. 6, pp. 682-687.

Freedberg, D., \& Gallese, V. (2007). Motion, emotion, and empathy in esthetic experience. Trends in Cognitive Sciences, Vol. 11, No. 5, pp. 197-203.

Fritz, T., Jentschke, S., Gosselin, N., Sammler, D., Peretz, I., Turner, R., Friederici, A.D., \& Koelsch, S. (2009). Universal recognition of three basic emotions in music. Current Biology, Vol. 19, No. 7, pp. 573-576.

Gabrielsson, A., \& Juslin, P.N. (1996). Emotional expression in music performance: Between the performer's intention and the listener's experience. Psychology of Music, Vol. 24, No. 1, pp. 68-91.

Gabrielsson, A., \& Lindström, E. (2001). The influence of musical structure on emotional expression. In: P.N. Juslin \& J. Sloboda (Eds.), Music and Emotion: Theory and Research. Oxford: Oxford University Press, pp. 223-248.

Gabrielsson, A., \& Lindström, E. (2005). Emotional expression in synthesizer and sentograph performance. Psychomusicology, Vol. 14, pp. 94-116.

Gabrielsson, A., \& Lindström, E. (2010). The role of structure in the musical expression of emotions. In: P.N. Juslin \& J. Sloboda (Eds.), Handbook of Music and Emotion: Theory, Research, and Applications. Oxford: Oxford University Press, pp. 367-400.

Gallagher, S., \& Sørensen, J.B. (2006). Experimenting with phenomenology. Consciousness and Cognition, Vol. 15, No. 26, pp. 119-134.

Gallese, V. (2010). Mirror neurons and art. In: F. Bacci \& D. Melcher (Eds.), Art and the Senses. Oxford: Oxford University Press, pp. 441-449.

Geiger, M. (1911). Über das Wesen und die Bedeutung der Einfühlung. In: F. Schumann (Ed.), Bericht über den IV. Kongreß für experimentelle Psychologie in Innsbruck vom 19. bis 22. April 1910. Leipzig: Barth, pp. 29-73.

Godøy, R.I., Haga, E., \& Jensenius, A.R. (2006). Exploring music-related gestures by sound-tracking: A preliminary study. In: K. Ng (Ed.), Proceedings of the COST287-ConGAS 2nd International Symposium on Gesture Interfaces for Multimedia Systems, 9-10 May 2006, Leeds, UK, pp. 27-33.

Hausegger, F.v. (1887). Die Musik als Ausdruck. Vienna: Carl Konegen.

Huron, D. (2006). Sweet Anticipation: Music and the Psychology of Expectation, Cambridge, MA: MIT Press. 
Jola, C., Davis, A., \& Haggard, P. (2011). Proprioceptive integration and body representation: insights into dancers' expertise. Experimental Brain Research, Vol. 213, Nos. 2-3, pp. 257-265.

Jola, C., Abedian-Amiri, A., Kuppuswamy, A., Pollick, F., \& Grosbas, M.H. (2012). Motor simulation without motor expertise: Enhanced corticospinal excitability in visually experienced dance spectators. PLoS ONE, Vol. 7, No. 3, p. e33343.

Juslin, P.N. (1997). Emotional communication in music performance: A functionalist perspective and some data. Music Perception, Vol. 14, No. 4, pp. 383-418.

Juslin, P.N. (2005). From mimesis to catharsis: Expression, perception, and induction of emotion in music. In: R. MacDonald, D.J. Hargreaves, \& D. Miell (Eds.), Musical Communication. Oxford: Oxford University Press, pp. 85-115.

Juslin, P.N., \& Laukka, P. (2004). Expression, perception, and induction of musical emotions: A review and a questionnaire study of everyday listening. Journal of New Music Research, Vol. 33, No. 3, pp. 217-238.

Juslin, P.N., \& Sloboda, J.A. (Eds.) (2001). Music and Emotion: Theory and Research. Oxford: Oxford University Press.

Juslin, P.N., \& Sloboda, J.A. (Eds.) (2010a). Handbook of Music and Emotion: Theory, Research, and Applications. Oxford: Oxford University Press.

Juslin, P.N., \& Sloboda, J.A. (2010b). The past, present, future of music and emotion research. In: P.N. Juslin \& J.A. Sloboda (Eds.), Handbook of Music and Emotion: Theory, Research, and Applications. Oxford: Oxford University Press, pp. 933-955.

Juslin, P.N., \& Timmers, R. (2010). Expression and communication of emotion in music performance. In: P.N. Juslin \& J.A. Sloboda (Eds.), Handbook of Music and Emotion: Theory, Research, and Applications. Oxford: Oxford University Press, pp. 453-489.

Juslin P.N., \& Västfjäll, D. (2008). Emotional response to music: The need to consider underlying mechanisms. Behavioral and Brain Sciences, Vol. 31, No. 5, pp. 559-575.

Juslin P.N., Västfjäll, D., \& Lundqvist, L. (2010). How does music evoke emotions? Exploring the underlying mechanisms. In: P.N. Juslin \& J.A. Sloboda (Eds.), Handbook of Music and Emotion: Theory, Research, and Applications. Oxford: Oxford University Press, pp. 605-642.

Keysers, C., \& Gazzola, V. (2009). Expanding the mirror: Vicarious activity for actions, emotions and sensations. Current Opinion in Neurobiology, Vol. 19, No. 6, pp. 666-671.

Kim, J.H. (2010). Towards embodiment-based research on musical expressiveness. In: S. Flach, D. Margulies, \& J. Söffner (Eds.), Habitus in Habitat I: Emotion and Motion. Bern: Peter Lang, pp. 245-260.

Kim, J.H., Demey, M., Moelants, D., \& Leman, M. (2010). Performance micro-gestures related to musical expressiveness. In: In S.M. Demorest, S.J. Morrison, \& P.S. Campbell (Eds.), Proceedings of the 11th International Conference on Music Perception and Cognition. Seattle, Washington: Causal Productions, pp. 827-833.

Kivy. P. (2001). Introduction to a Philosophy of Music. Oxford: Clarendon Press.

Koelsch, S. (2009). Music-syntactic processing and auditory memory: similarities and differences between ERAN and MMN. Psychophysiology, Vol. 46, No. 1, pp. 179-190.

Koelsch, S. (2011). Towards a neural basis of processing musical semantics. Physics of Life Reviews, Vol. 8, No. 2, pp. 89-105.

Koelsch, S., Fritz, T., Schulze, K., Alsop, D., \& Schlaug, G. (2005). Adults and children processing music: 
an fMRI study. NeuroImage, Vol. 25, No. 4, pp. 1068-1076.

Küssner, M.B., Prior, H.M., Gold, N.E., \& Leech-Wilkinson, D. (2012). Getting the shapes "right" at the expense of creativity? How musicians' and non-musicians' visualizations of sound differ. In: E. Cambouropoulos, C. Tsougras, P. Mavromatis, \& K. Pastiadis (Eds.), Proceedings of the 12th International Conference on Music Perception and Cognition, 23-28 July 2012, Thessaloniki, Greece, p. 561.

Langer, S.K. (1960 [1957]). Expressiveness and symbolism. From Problems of Art (1957). In: M. Rader (Ed.), A Modern Book of Esthetics: An Anthology (3 $3^{\text {rd }}$ Edition). New York: Holt, Rinehart and Winston, pp. 248-258.

Levinson, J. (2006). Musical expressiveness as hearability-as-expression. In: M. Kieran (Ed.), Contemporary Debates in Aesthetics and the Philosophy of Art. Malden, MA/Oxford: Blackwell, pp. 192-204.

Lipps, T. (1900). Aesthetische Einfühlung. Zeitschrift für Psychologie und Physiologie der Sinnesorgane, Vol. 22, pp. 415-450.

Lipps, T. (1903). Einfühlung, innere Nachahmung, und Organempfindungen. Archiv für die gesamte Psychologie, Vol. 1, pp. 185-204.

Lutz, A., Lachaux, J.P., Martinerie, J., \& Varela, F. (2002). Guiding the study of brain dynamics by using first-person data: Synchrony patterns correlate with ongoing conscious states during a simple visual task. Proceedings of the National Academy of Sciences, Vol. 99, No. 3, pp. 1586-1591.

Meyer, L.B. (1956). Emotion and Meaning in Music. Chicago/London: The University of Chicago Press.

Northoff. G., \& Heinzel, A. (2006). First-Person Neuroscience: A new methodological approach for linking mental and neuronal states. Philosophy, Ethics, and Humanities in Medicine, Vol. 1, No. 3.

Petitmengin, C. (2006). Describing one's subjective experience in the second person: An interview method for the science of consciousness. Phenomenology and Cognitive Science, Vol. 5, Nos. 3-4, pp. 229-269.

Petitmengin, C. (2007). Towards the source of thoughts: The gestural and transmodal dimension of lived experience. Journal of Consciousness Study, Vol. 14, No. 3, pp. 54-82.

Petitmengin, C. (2011). Describing the experience of describing? The blind spot of introspection. Journal of Consciousness Study, Vol. 18, No. 1, pp. 44-62.

Petitmengin, C., Baulac, M., \& Navarro, V. (2006). Seizure anticipation: Are neurophenomenological approaches able to detect preictal symptoms? Epilepsy \& Behavior, Vol. 9, No. 2, pp. 298-306.

Petitmengin, C., Navarro, V., \& Le Van Quyen, M. (2007). Anticipating seizure: Pre-reflective experience at the center of neurophenomenology. Consciousness and Cognition, Vol. 16, No. 3, pp. 746-764.

Pigman, G.W. (1995). Freud and the history of empathy. The International Journal of Psycho-Analysis, Vol. 76, No. 2, pp. 237-256.

Rizzolatti, G., \& Sinigaglia, C. (2007). Mirrors in the Brain: How Our Minds Share Actions, Emotions, and Experience. Oxford: Oxford University Press.

Scherer, K.R. (2004). Which emotions can be induced by music? What are the underlying mechanisms? And how can we measure them? Journal of New Music Research, Vol. 33, No. 3, pp. 239-251.

Scherer, K.R., \& Zentner, M. R. (2001). Emotional effects of music: production rules. In: P.N. Juslin \& J.A. Sloboda (Eds.), Music and Emotion: Theory and Research. Oxford: Oxford University Press, pp. 361-387. 
Schubert, E. (2010). Continuous self-report methods. In: P.N. Juslin \& J.A. Sloboda (Eds.), Handbook of Music and Emotion: Theory, Research, and Applications. Oxford: Oxford University Press, pp. 223-253.

Stern, D.N. (1985). The Interpersonal World of the Infant. New York: Basic Books.

Stern, D.N. (2010). Forms of Vitality: Exploring Dynamic Experience in Psychology, the Arts, Psychotherapy, and Development. New York: Oxford University Press.

Tillmann, B. (2005). Implicit investigations of tonal knowledge in nonmusician listeners. Annals of the New York Academy of Science, Vol. 1060, pp. 100-110.

Tillmann, B., Janata, P., \& Bharucha, J. (2003). Activation of the inferior frontal cortex in musical priming. Cognitive Brain Research, Vol. 16, No. 2, pp. 145-161.

Truslit, A. (1938). Gestaltung und Bewegung in der Musik. Berlin: Chr. Friedrich Vieweg.

Varela, F.J. (1996). Neurophenomenology. Journal of Consciousness Study, Vol. 3, No. 4, pp. 330-349.

Zentner, M., Grandjean, D., \& Scherer, K.R. (2008). Emotions evoked by the sound of music: Characterization, classification, and measurement. Emotion, Vol. 8, No. 4, pp. 494-521. 